\title{
Biological and urban environmental variables as correlates of adolescents' physical activity
}

\author{
Variáveis biológicas e do ambiente urbano como correlatos da atividade física de \\ adolescentes
}

\section{AUTHOR'S \\ Júlio Brugnara Mello ${ }^{1}$ (D) \\ Michael Duncan² (D) \\ Arieli Dias ${ }^{1}$ (D) \\ Gabriel Bergmann ${ }^{3}$ (D) \\ Anelise Reis Gaya ${ }^{1}$ (D) \\ Adroaldo Gaya ${ }^{1}$ (D) \\ 1 Universidade Federal do Rio Grande do Sul, Programa de Pós-Graduação em Ciências do Movimento Humano. Porto Alegre, Rio Grande do Sul, Brasil. \\ 2 Centre for Sport, Exercise and Life Sciences Coventry University, Coventry, United Kingdom. 3 Universidade Federal de Pelotas, Laboratório de Estudos em Esporte Coletivo, Pelotas, Rio Grande do Sul, Brasil.}

\section{CORRESPONDING}

Júlio Brugnara Mello

juliobmello@hotmail.com

Rua Felizardo, 750, Jardim Botânico

Porto Alegre. Escola de Educação Física,

Fisioterapia e Dança da Universidade Federal do Rio Grande do Sul. Prédio LAPEX.

CEP: 90690-200.

\section{DOI}

10.12820/rbafs. $25 \mathrm{e} 0134$

\section{(cc) BY}

This work is licensed under a Creative Commons Attribution 4.0 International License.

\begin{abstract}
The aim of this study was to examine the biological and urban environment variables that associate with physical activity (PA) in adolescents. After this, to examine the interrelationship between biological, urban environment variables and PA in structural equation analysis. This was a cross-sectional study with an adolescents' randomized sample. Measures included PA (steps per day by pedometers); self-report questionnaire; geographical location; 'geocoding' process; and direct observation and cardiorespiratory fitness (by 6-min run test). Linear and binary logistic regression models were tested. In addition, moderation and mediation analysis were tested. The sample consisted of $236 \mathrm{ad}-$ olescents ( $61.9 \%$ girls) aged 14 to 18 years. The commuting to school was associated with residence distance to school (OR = 6.41; CI95\%: 1.01-40.80) and walkability ( $\mathrm{OR}=1.40$; CI95\%: 1.02-1.94). The gender moderates the relationship between walkability and commuting to school, association only in girls $(\mathrm{OR}=1.72 ; \mathrm{p}<0.05)$. The relationship between the use of public spaces and PA was reduced $(\Delta \beta=-1320.6$ steps/day; $\mathrm{p}<0.05)$ in the presence of cardiorespiratory fitness (mediation effect). In conclusion, adolescents' PA is associated with the use of public spaces, but this relation is mediated by cardiorespiratory fitness. In addition, PA is associated with commuting to school. This commuting is associated with residence distance to school and walkability just in girls.
\end{abstract}

Keywords: Built Environment; Public space; Public health; Motor activity; Young.

RESUMO

O objetivo deste estudo foi examinar as variáveis biológicas e do ambiente urbano que se associam à atividade física $(A F)$ em adolescentes. Em seguida, examinar a inter-relação entre variáveis biológicas, do ambiente urbano e AF em uma análise de equaçôes estruturais. Estudo transversal com amostra randomizada de adolescentes. As medidas incluíram AF (passos/dia por pedômetros); questionário de autorrelato; localização geográfica; processo de 'geocodificação'; observação direta e aptidão cardiorrespiratória (por teste de corrida de $6 \mathrm{~min}$ ). Modelos de regressão logística linear e binária foram testados. Além disso, análises de moderação e mediação foram testadas. A amostra foi composta por 236 adolescentes (61,9\% meninas) de 14 a 18 anos. $O$ deslocamento até a escola esteve associado à distância entre a residência e a escola $(O R=$ 6,41; IC95\%: 1,01-40,80) e ao walkability (OR = 1,40; IC95\%: 1,02-1,94). O gênero modera a relação entre o walkability e deslocamento para a escola, associação apenas em meninas $(O R=1,72 ; p<0,05)$. A relação entre o uso de espaços públicos e $A F$ foi reduzida $(\Delta \beta=-1320,6$ passos/dia; $p<0,05)$ na presença de aptidão cardiorrespiratória (efeito mediador). Concluindo, a AF de adolescentes está associada ao uso de espaços públicos, mas essa relação é mediada pela aptidão cardiorrespiratória. Além disso, a AF está associada ao deslocamento para a escola. Esse deslocamento está associado à distância entre a residência e a escola e ao walkability apenas em meninas.

Palavras-chave: Ambiente construído; Espaço público; Saúde pública; Atividade motora; Jovem.

\section{Introduction}

Regular physical activity (PA) during adolescence is related to a number of short- and long-term health benefits ${ }^{1}$, including increased cardiorespiratory fitness and reduced risk of cardiovascular diseases ${ }^{2}$. Despite these benefits, research suggests that the time spent in physical activities of moderate to vigorous intensity is decreasing in this population ${ }^{3}$. As moderate to vigo- rous PA is a key modifiable behavior for health and as adoption/maintenance of this behavior is multifactorial $^{4}$, understanding the relations between PA and its possible correlates is an important first step in targeting interventions to enhance adolescent health.

In this sense, the set of factors that have been associated with PA is divided into four main contexts: biological, sociocultural, psychosocial and environmental ${ }^{5}$. 
Among biological and sociocultural factors, positive associations are observed between PA and self-efficacy, self-regulation, physical fitness, sports preferences and motivation. However, the females' gender and the advance of age present negative association with PA, in adolescence mainly $y^{6,7}$. In particular, physical fitness, especially cardiorespiratory fitness, is a factor that has been most investigated given the potential PA's effect and to be an important variable for maintenance/engagement in PA during adolescence ${ }^{6,8}$.

In relation to the environmental context, there are indications that the characteristics of the urban environment influence the level of PA of adolescents ${ }^{9,10}$. In particular, the quality of built structures in squares, parks, and schools have been identified as contributors/ barrier to PA in adolescents ${ }^{11}$. However, other characteristics such as the quality of access structures such as streets, bicycle paths, and sidewalks seem to facilitate the active displacement to these specific places ${ }^{11,12}$. In the case of adolescents, these environmental aspects are factors that contribute to regular PA, especially in relation to commuting to school on a daily basis ${ }^{13,14}$.

In the context of human behavior, and PA specifically, it is necessary to understand more than the relation between two variables in order to effectively change behavior. The principle of ecological models of health behaviors ${ }^{5}$, have been used to analyses the PA correlates, especially the urban environment, school environment an engaging in sports in adolescents context ${ }^{6,12,13}$.

In this case, considering cardiorespiratory fitness, along with behavioral variables, such as sports practice, for example, can add important evidence in understanding the relationship between environment variables and $\mathrm{PA}$ in adolescence. Therefore, the aim of this study was to examine the biological and urban environment variables that associate with PA in adolescents. After this, to examine the interrelationship between biological, urban environment variables and $\mathrm{PA}$ in structural equation analysis.

\section{Methods}

This study used a cross-sectional and quantitative design to understand the relations between PA, urban environment and biological variables. A team of researchers and students (undergraduate and graduate) trained on the study procedures performed all steps of data collection from February to June 2016. The research project entitled "Aptidão cardiorrespiratória, composição corporal e atividade física de adolescentes: associa- ção com o ambiente escolar, com a estrutura pedagógica da educação física e com o ambiente urbano" was approved by the Human research Ethics Committee of Universidade Federal do Rio Grande do Sul, under number 1.338.597 (CAAE: 48784215.5.0000.5347).

Adolescents enrolled in high school in public schools of the southern zone of Porto Alegre, capital of the state of Rio Grande do Sul, Brazil took part in this study. Porto Alegre has approximately 28000 high school students in 51 public schools (28140 according to the 2014 Brazilian census). Of this total, the south zone comprises about $11.0 \%$ of the students, corresponding to 3095 students, coming from seven public schools.

To calculate the sample size, the following criteria were considered: a) an estimated population of 3095 students; b) 2016 proportion of 80\% (low cardiorespiratory fitness and insufficient PA) ${ }^{3}(\mathrm{p}) ; \mathrm{c}$ ) complementary percentage of 100 - p; d) 95\% confidence interval; and (e) an acceptable sampling error of five percentage points. Following consideration of these criteria, it was estimated that 236 students were needed. The power of analysis and the effect size estimated from the needed sample ( $n=236)$ were calculated using the $G^{*}$ power software version 3.1.9.2. Considering the most demanding analyses (linear regression) the estimated effect size was large $(0.35)$ and the power of analyses was high $(\beta>0.90)$.

A multiple-phase procedure was used for the recruitment of the sample. First, the southern zone of the city was divided into three regions, according to the "municipal director plan" (center south, south, and far south). These regions differ in economic and cultural characteristics, justifying the selection of a school in each region. Cluster sampling was then used where a school from each region was selected randomly.

In order to select public schools, were identified as the schools' addresses from the website of the 1st Regional Education Coordination. In each selected school, a face-to-face meeting with the director of each school then took place where the research objectives and requirements for participants were presented. Following this, a formal invitation was made to the school. Once the school agreed to participate in the study, high school classes were listed. After that, a simple draw was carried out and three classes were selected (clusters). Then the students (and their parents) were invited to participate in the study.

The eligibility criteria for adolescents to participate in the study were: 1) Attendance $>60 \%$ in school; 2) been into age group; 3) absence of injury(is) that mod- 
ified the normal habits, including physical education (PE), sports and commuting to school. After data collection, the non-eligibility criteria were: 1 ) incorrect use of the pedometers; 2) not providing the correct address; 3) not answering any question of the questionnaire.

The level of PA was determined by the number of steps/day recorded by pedometers (Yamax Digi-Walker CW 700). Each individual used a pedometer for three consecutive weekdays. Three days of monitoring is a sufficient length of time to determine habitual physical activity levels. This is evidenced in Brazilian adolescents, specifically ${ }^{16}$. The adolescents were initially instructed where to place the pedometer (waist), how to wear the pedometer (attached by an elastic belt given by the assessment team), the functioning of memory, and when not to wear the pedometer e.g., while conducting activities involving water (such as swimming and bathing) and while they slept. The average number of steps across the three days was used as a measure of each participants PA level. Participants who accrued daily step counts of less than 1000 steps/ day or over 30000 steps/day in at least two days were excluded from subsequent analysis ${ }^{16}$.

In addition to the pedometer-based PA assessment, the researchers created a self-report questionnaire which was used to collect additional information. This was used to add contextual information to the steps/ day PA data.

The questionnaire questions were: 1 ) Do you do PA outside the school? (yes or not), if yes, how many days per week and time per day; 2) Do you do oriented PA, such as gym, dance, sports or activities in general? (yes or not), if yes, how much days per week and time per day; 3) Do you do school PE? (yes or not); 4) Do you like to do PA, such as gym, dance, sports or activities in general? (yes or not); 5) Do you like to do school PE? (yes or not); 6) How do you commute to school on most days of the week? (walking, biking/skating, on car, on bus or other); Do you use public spaces (parks, squares, streets, bicycle path) to do PA? (yes or not).

The gender and age were assessed in the PA questionnaire. In order to assess cardiorespiratory fitness, the adolescents performed the 6-minute run/walk test. This test is valid and used in Brazilian children and adolescents as a predictor of peak oxygen uptake ${ }^{17}$. The test was performed in small groups of adolescents (approximately 10). The test was performed on a rectangular track demarcated by cones. Before starting the test, the team of evaluators measured the total perimeter of the track (one lap). The adolescents were instructed to cover as many laps of the track as possible in 6 minutes. The test began with the sound of a whistle, a second whistle was used to signal to participants that there was one minute of the test remaining, with a third whistle indicating the end of the 6-minute period. The total number of laps and corresponding distance covered in meters during the 6-minute period was recorded and taken as a measure of cardiorespiratory fitness.

In order to understand the potential association between PA, urban environment and cardiorespiratory fitness the home address of each adolescent was used as a key geographical location. In addition, the schools' address, the location of the public spaces and spatial information from georeferencing were used to association analysis.

The Municipal Environment Secretariat and the Public Transport and Movement Company of Porto Alegre, Brazil, made the list of all parks, squares and bicycle paths of the city. Initially, 109 squares/parks and one cycle path in the south of the municipality were identified in the list of the municipal government of Porto Alegre. After verifying the addresses and site visits, seven spaces were discarded from the study because they did not have minimum conditions for use (bush, forest, surrounded by walls, with constructions inside the space) and four spaces were not located in the addresses indicated in the list and in a radius of 200 meters. Therefore, 98 squares and little parks and one cycle path (Figure 1) were evaluated and georeferenced. In the Porto Alegre's south zone has no big parks, that way, in this study the squares and little parks were grouped in a category called "parks/squares".

For georeferencing analysis, the Porto Alegre City Observatory provided all municipality's spatial information. The information was provided in different spatial data set containing street intersection number (IntS), mean square size (Xsq) and residential density (RD). A specialized team from the Municipal Information System, of the Porto Alegre, Brazil, assessed this data. In addition, information was also provided on the socioeconomic indicators generated by municipal public agencies, stratified by neighborhoods and city-regions. All this information is made available to the general public at the Porto Alegre City Observatory.

In the present study, the use of spatial data was conducted through Geographic Information Systems, performed in ArcGIS 10.2.1 software (ESRI). The geoprocessing was performed in four steps: 1) combining individual information (home address of each adoles- 
cent and schools' address) into a spatial data set; 2) visit in each public space for confirming the location; 3 ) combining individual information and public space information into a spatial data set; and 4) all information was superimposed on a map (with streets, and other urban information) and analyzed in an integrated way.

For creating the environmental variables, first, we created the buffer from the limits of the adolescents' residence (centroid). From centroid, we demarcated points with 500 meter of distance, these points have traced a line through the possible walking access points (e.g. sidewalks). In Porto Alegre's urban organization, 500 meters walking allows access on a minimum of 10 residential squares in the neighborhood.

The evaluation of public spaces was completed using direct observation. The research team visited all the places listed in the south zone of Porto Alegre. At each visit, the entire length of each site was covered and evaluation was carried with Physical Activity Resource Assessment $(\mathrm{PARA})^{18}$. The data were described by the researchers, based on an instrument manual, on an ordinal scale of four items: (0) absence of structure and qualities; (1) poor; (2) average; (3) good. For this study, we did not use the quality evaluation, only the presence or not of PA structure.

From these procedures, the following variables were determined: 1) Have square/park in 500-meter-buffer (at least one); 2) Have square/park with PA attributes (without playground); 3) Residence distance to nearest square/par; 4) Residence distance to school; and; 5) walkability. The distances were considered from the smallest distance travelled walking by footpaths (sidewalks). The walkability was then determined using the following available variables: street intersection number (IntS), mean square size (Xsq) and residential density (RD), all within each buffer, therefore for each subject. Walkability was calculated from the equation Walkability $=$ Zscore IntS + Zscore Xsq + Zscore RD and classified dichotomously (from the 75 th percentile as "displacement-friendly" and below the 75 th percentile as "non-displacement") ${ }^{19,20}$.

For the data treatment, descriptive and association analysis was undertaken. Absolute and relative frequencies and their respective $95 \%$ confidence intervals were presented for the categorical variables and the mean and standard deviation for the continuous variables. The normality of the variables was verified with the Shapiro-Wilk test and any differences between the genderes were determined using chi-square and student's t-tests.

In order to determine the association between vari- ables, categories were created for distance variables (to the school and to the nearest public space). These classifications took into account the following: for the school the maximum distance of the buffer $(500 \mathrm{~m})$, and twice this distance $(1000 \mathrm{~m})$; to the public space closest to half the maximum buffer distance $(250 \mathrm{~m})$. Students who lived outside the southern zone or whose buffer exceeded the southern boundary did not enter into the analysis of the quantity of public spaces within the buffer.

To verify the variability of PA from the biological variables, different linear regression models were tested, the analysis was performed in crude and adjusted fashion for gender and age. The association between the biological variables that were associated with PA and environmental variables were analyzed using different models of binary logistic regression. In the case of missing data, the analysis was performed and the power of the test was calculated, the results were considered when the power of test maintaining proximity to the general sample calculation.

Any mediation of the relationship between biological variables and PA was then established. First possible mediating variables were chosen from theoretical hypotheses. Linear regression analysis was then performed, indirect effects (effect with the presence of the mediator variable) and to verify if the results supported the effect of mediation, the Sobel test was applied. For all analyzes, an alpha of 0.05 was considered a priori. All data was analyzed using the Statistical Package for the Social Sciences (IBM-SPSS 20.0).

\section{Results}

The sample consisted of 236 adolescents (61.9\% girls) aged

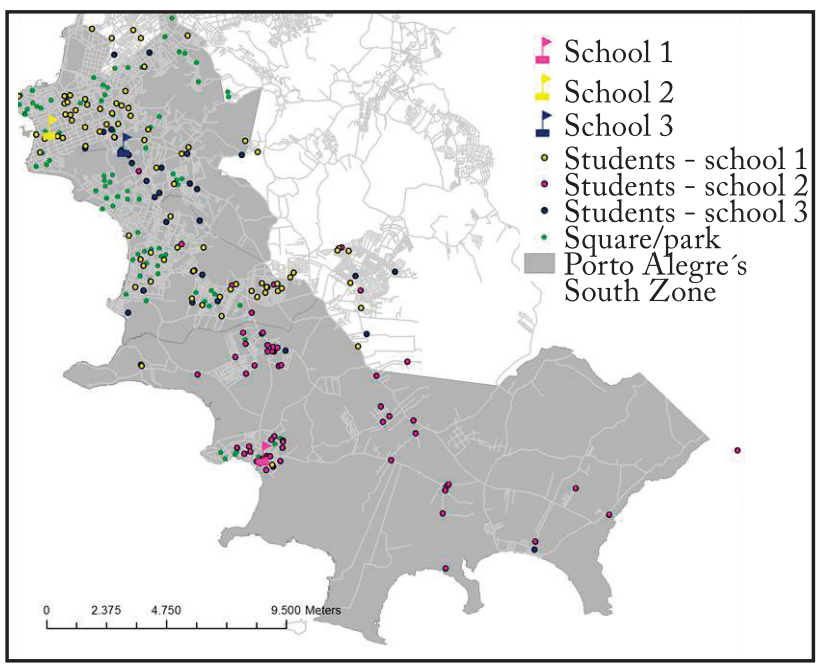

Figure 1 - Distribution of adolescents' residence stratified by schools, Porto Alegre's South zone, 2016. 
14 to 18 years. Figure 1 shows the distribution of adolescents according to their place of residence in the south, 180 adolescents had the address provided by the parents (requirement of the georeferencing analysis), and 14 ado- lescents resided outside the south zone and were recorded as sample loss in the variables related to public spaces.

The characteristics of the sample are shown in $\mathrm{Ta}-$ ble 1 . The PA level ( $\Delta: 2286$ steps) and cardiorespirato-

Table 1 - Description of characteristics of adolescents and their respective residence area (500-meter-buffer), Porto Alegre's South zone, 2016

\begin{tabular}{|c|c|c|c|c|c|c|c|}
\hline \multicolumn{8}{|c|}{ Biological variables } \\
\hline & \multicolumn{3}{|c|}{ Girls } & \multicolumn{3}{|c|}{ Boys } & \multirow[b]{2}{*}{$\mathrm{p}$} \\
\hline & $\mathrm{N}$ & $\dot{\mathrm{x}}$ & $\mathrm{SD}$ & $\mathrm{N}$ & $\dot{\mathrm{x}}$ & $\mathrm{SD}$ & \\
\hline PA (number of steps) & 122 & 7192.0 & 3283.8 & 69 & 9478.5 & 4575.7 & 0.001 \\
\hline \multirow[t]{2}{*}{ CRF (meters) } & 110 & 757.2 & 124.7 & 68 & 976.8 & 167.3 & 0.001 \\
\hline & $\mathrm{N}$ & $(\%)$ & CI 95\% & $\mathrm{N}$ & $(\%)$ & CI 95\% & $\mathrm{p}$ \\
\hline Oriented PA & & & & & & & 0.018 \\
\hline Yes & 49 & 33.6 & $26.0-41.1$ & 24 & 26.7 & $17.8-36.7$ & \\
\hline Not & 97 & 66.4 & $58.9-74.0$ & 66 & 73.3 & $63.3-82.2$ & \\
\hline School PE participation & & & & & & & 0.042 \\
\hline Yes & 108 & 74.0 & $66.4-80.8$ & 78 & 86.7 & $78.9-93.3$ & \\
\hline Not & 38 & 26.0 & $19.2-33.6$ & 12 & 13.3 & $6.7-21.1$ & \\
\hline Use public space to PA & & & & & & & 0.015 \\
\hline Yes & 35 & 24.0 & $17.1-30.1$ & 35 & 38.9 & $30.0-50.0$ & \\
\hline Not & 111 & 76.0 & $69.9-82.9$ & 55 & 61.1 & $50.0-70.0$ & \\
\hline Commuting to school & & & & & & & 0.117 \\
\hline Active & 52 & 35.6 & $28.1-43.8$ & 40 & 44.4 & $34.4-54.4$ & \\
\hline Passive & 94 & 64.4 & $56.2-71.9$ & 50 & 55.6 & $45.6-65.6$ & \\
\hline Like school PE & & & & & & & 0.009 \\
\hline Yes & 87 & 67.4 & $59.7-76.0$ & 75 & 86.2 & $78.2-93.1$ & \\
\hline Not & 42 & 32.6 & $24.0-40.3$ & 12 & 13.8 & $6.9-21.8$ & \\
\hline Like practice $\mathrm{PA}$ & & & & & & & 0.601 \\
\hline Yes & 123 & 84.8 & $78.6-90.3$ & 72 & 82.8 & $74.7-90.8$ & \\
\hline Not & 22 & 15.2 & $9.7-21.4$ & 15 & 17.2 & $9.2-25.30$ & \\
\hline PA outside school & & & & & & & 0.283 \\
\hline Yes & 62 & 42.5 & $33.6-50.0$ & 46 & 51.1 & 41.1-61.1 & \\
\hline Not & 84 & 57.5 & $50.0-66.4$ & 44 & 48.9 & $38.9-58.9$ & \\
\hline \multicolumn{8}{|c|}{ Environment variable } \\
\hline Have square/park in buffer (at least one) & & & & & & & 0.719 \\
\hline Yes & 38 & 36.9 & $27.2-45.6$ & 25 & 39.7 & $28.6-52.4$ & \\
\hline Not & 65 & 63.1 & $54.4-72.8$ & 38 & 60.3 & $47.6-71.4$ & \\
\hline $\begin{array}{l}\text { Have square/park with PA attributes } \\
\text { (without playground) }\end{array}$ & & & & & & & 0.696 \\
\hline Yes & 25 & 24.3 & $16.5-32.0$ & 17 & 27.0 & $15.9-38.1$ & \\
\hline Not & 78 & 75.7 & $68.0-83.5$ & 46 & 73.0 & $61.9-84.1$ & \\
\hline Residence distance to nearest square/park & & & & & & & 0.713 \\
\hline$<250$ meters & 22 & 21.4 & $13.6-30.1$ & 15 & 23.8 & $14.3-34.9$ & \\
\hline$>250$ meters & 81 & 78.6 & $69.9-86.4$ & 48 & 76.2 & $65.1-85.7$ & \\
\hline Residence distance to school & & & & & & & 0.186 \\
\hline$<500$ meters & 4 & 3.6 & $0.9-7.1$ & 5 & 7.4 & $1.5-14.7$ & \\
\hline 501-1000 meters & 10 & 8.9 & $4.5-14.3$ & 8 & 11.8 & $4.4-20.6$ & \\
\hline$>1001$ meters & 98 & 87.5 & $81.3-92.9$ & 55 & 80.9 & $72.1-89.7$ & \\
\hline Walkability & & & & & & & 0.287 \\
\hline Displacement-friendly & 25 & 22.3 & $15.2-29.5$ & 20 & 29.4 & $19.1-41.2$ & \\
\hline Non-displacement & 87 & 77.7 & $70.5-84.8$ & 48 & 70.6 & $58.8-80.9$ & \\
\hline
\end{tabular}

$\mathrm{N}=$ number $\dot{\mathrm{x}}=$ mean value; $\mathrm{SD}=$ standard deviation; $\%$ = percent CI95\% = Confidence interval of $95 \% ; \mathrm{p}=$ significance level; $\mathrm{PA}=$ physical activity; $\mathrm{PE}=$ physical education $\mathrm{CRF}=$ cardiorespiratory fitness. 
ry fitness $(\Delta: 219$ meters) were statistically significant for boys when compared to girls $(\mathrm{p}<0.01)$. Likewise, responses on the questionnaire to: "like school PE" $(\Delta$ : $18.8 \%)$ and the use of public spaces to $\mathrm{PA}(\Delta: 14.9 \%)$ were significantly different between boys and girls, with boys reporting more positive responses than girls.

The results indicate that the commuting to school, use of public spaces and cardiorespiratory fitness predicted PA variability. Together with cardiorespiratory fitness. Together and adjusted to gender and age predict approximately $19 \%$ of PA variability (Table 2). The complementary results that supported the construction of the structural equation are described in supplement 1 .

The variables, cardiorespiratory fitness, "Like practice PA" and "practice PA outside school" were tested as mediators of the relationship between the use of public spaces and PA. However, there was evidence of cardiorespiratory fitness mediation in relation to the use of public spaces-PA (Sobel ( $\mathrm{z}):-2.88 ; \mathrm{p}=0.003$ ), with a reduction of the beta value for $\beta=-2279.1(\Delta: \beta=461)$ indicating an indirect effect of the use of public spaces on $\mathrm{PA}$ of $\beta=-958.8$.

Figure 2 summarizes the associations found in all analyses. Active commuting to school was associated with two environmental variables. This association was not maintained after adjusting, indicating moderation possibility. After testing, the results showed that gender moderates the relationship between non-displacement walkability and passive commuting to school.

This was however only significant for girls and was significant regardless of the distance to school. The use of public spaces was not associated to the other variables in this study, however its relation with PA was reduced in the presence of cardiorespiratory fitness, this indicate that cardiorespiratory fitness moderate the relationship between PA and use of public spaces.

\section{Discussion}

The results of the current study present a structural model of adolescents' PA correlates. The main results identifying the relationship between PA evaluated by steps/

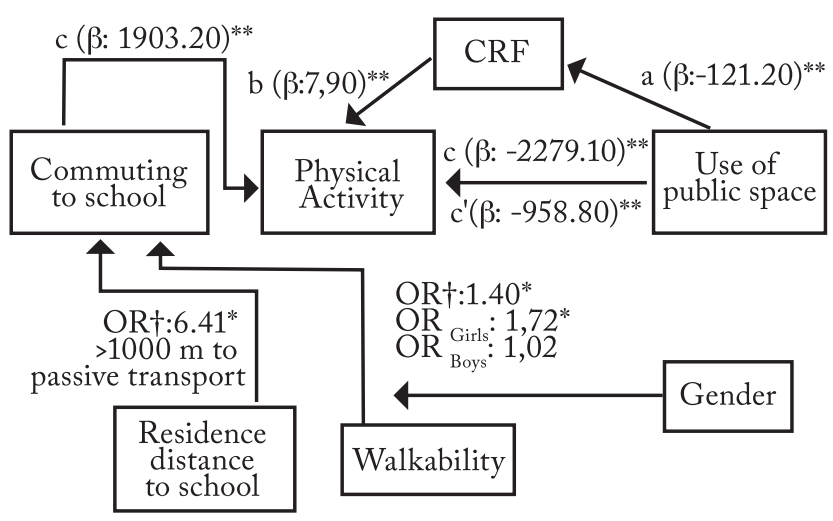

Figure 2 - Effect of urban environmental and biological variables on adolescents' physical activity. Porto Alegre, Brazil, 2016.

$a=$ is the effect of use of public space on cardiorespiratory fitness; $b$ $=$ is the effect of cardiorespiratory fitness on physical activity; $\mathrm{c}=$ is the effect of use of public space on physical activity; $c^{\prime}=$ denote the effect of use of public space on physical activity when including cardiorespiratory fitness as a mediator; $\mathrm{OR} \dagger$ is the odds ratio without adjust; OR girls and OR boys is the odds ratio for each gender; ${ }^{*}$ is the $\mathrm{p}$ value less than 0.05 ; $^{*}$ is $\mathrm{p}$ value less than 0.01 .

day and urban environmental variables, cardiorespiratory fitness and behaviors variables such as commuting to school and use of public spaces to PA. The evaluation of public spaces shows that there is an equivalent distribution, which covers the entire area of the three evaluated regions. The "extreme south" region presents (Figure 1) specific characteristics that resemble rural areas, such as large green areas. This fact justifies the smaller number of squares/parks, but well distributed in the main urban area of the region. In all south zone of Porto Alegre no have big parks with attributes to PA practice and green areas into space.

Approximately $60 \%$ of the adolescents did not have a public space within a radius of 500 meters of their residence. In addition, of the adolescents who have public space, only $26 \%(25-27 \%)$ have some attribute for the practice of physical activities. In this sense, squares/parks with few options for physical activity may limit the practices of more intense activities, like different sports practices.

There is no consensus in the literature about the proximity of public spaces to the residence of adoles-

Table 2 - Variability estimation of physical activity from biological variables, Porto Alegre's South zone, 2016.

\begin{tabular}{|c|c|c|c|c|c|c|}
\hline \multirow{2}{*}{$\mathrm{R}^{2}=0.194$} & \multicolumn{3}{|c|}{ Physical activity } & \multirow[b]{2}{*}{$\beta^{*}$} & \multirow[b]{2}{*}{ CI 95\% } & \multirow[b]{2}{*}{$\mathrm{p}$} \\
\hline & $\beta$ & CI 95\% & $\mathrm{p}$ & & & \\
\hline Commuting to school & -1903 & $-3050-755$ & 0.001 & -770.4 & $-2997--543$ & 0.005 \\
\hline Use of public space & -2740 & $-3931-1550$ & 0.001 & -258.7 & $-3619--898$ & 0.001 \\
\hline CRF & 9.95 & $6.27-13.71$ & 0.001 & 7.26 & $2.55-11.98$ & 0.003 \\
\hline
\end{tabular}

$\beta=$ beta value $\beta^{*}=$ beta value adjusted to gender and age; $\mathrm{p}=$ significance level; CI95\%: = confidence interval of $95 \% ; \mathrm{R}^{2}=$ determination coefficient; $\mathrm{CRF}$ = cardiorespiratory fitness. 
cents, regardless of the structures they have, as an important factor for the promotion of physical activity. A recent literature review has shown that the results on this relationship are inconsistent even when evaluating physical activity with objective measures ${ }^{12}$. Similarly, in a large rural center of Western Australia, all parks were evaluated and adolescents indicated which park they frequently used, of the 751 adolescents, only $27 \%$ reported using the park closest to their home ${ }^{21}$.

Our results indicate that having a public space (within the $500 \mathrm{~m}$ buffer) with attributes such as sports courts, exercise stations and runways was not associated with physical activity in our sample of Brazilian adolescents. These findings are contrary to another Brazilian study that indicated that the quantity, specificity, diversity and quality of existing structures are positively associated with the practice of physical activity of young people in public spaces ${ }^{22}$. However, in the present study, the pedometers evaluation and the PA indicators differed to those used by Reis et al. ${ }^{22}$ that used a questionnaire and interview for access PA indicators and environment variables. This may explain the discrepancy between the results of the current study and that of prior work.

In addition, a mediating effect of cardiorespiratory fitness was found. This means that the presence of cardiorespiratory fitness weakens the relationship between physical activity and use of public spaces. Cardiorespiratory fitness is strongly associated with physical activity in adolescence ${ }^{23}$, being a potent factor in the prevention of overweight and obesity. In this sense, the mediation is evidence that adolescents with low levels of cardiorespiratory fitness may use parks less for physical activity, however, the design of study do not permit attribute causal relation. It is possible to speculate from results that less able adolescents have a tendency to less involvement with physical activities. On the other hand, adolescents with better levels of cardiorespiratory fitness may be more likely to engage in physical activities. In the context of our results, this can occurs with PA in public spaces.

Adolescence is also a period of personality formation and major social changes, the level of cardiorespiratory fitness and self-perception in relation to their physical state (or physical capacity) are barriers to the practice of physical activities ${ }^{24}$, especially in public places or with the presence of other persons. Corroborating our findings, a Brazilian study showed that among the facilitators, reported in focus groups, for physical activities in adolescents between the ages of 14 and 17, were "having skills" and "having worked physical abilities in school $\mathrm{PE}^{25}$, which in our hypothesis may be associated with the level of cardiorespiratory fitness of the young.

In this sense, it is important to realize that the use of public spaces was an influential factor in the physical activity of adolescents, regardless of distance. Although our findings indicate a mediation of cardiorespiratory fitness, the influence of the use of public spaces in physical activity agrees with other studies in the area ${ }^{26}$. Likewise, active commuting to school was also a factor associated with the physical activity of adolescents. This factor is well evidenced in the literature as an important promoter of good levels of physical activity ${ }^{14,27}$.

The present study also aimed to identify possible relationships in perspective of the structural equation model. In regard to this aim, our results indicated that the distance between residence and school and walkability are associated with the type of commuting to school but only for girls. For both boys and girls, residing at a distance greater than 1000 meters was associated with passive commuting to school. These results point to distances shorter than that of an American study that investigated 1554 girls and found that residing five miles (approximately 8000 meters) was strongly associated with low levels of moderate-vigorous physical activity, in addition to highlighting a negative association between the time in physical activity and the distance between residence and school ${ }^{28}$.

In addition to these results, we identified a moderating effect of gender on the association between passive commuting and non-displacement walkability. This effect indicated an association only for girls. Recently, Sallis et al. ${ }^{29}$ demonstrated that in American adolescents neighborhood walkability was strongly associated with active commuting and physical activity for both boys and girls. However, our study presents evidence that there are different factors that explain the active commuting of adolescents (boys and girls).

Considering that the shorter distance is associated with the active form of commuting to school, for girls, it is also important that the transit capacity is favorable. In Brazil, there are currently a high number of cases of violence against women and this can be a decisive barrier for parents to allow active commuting to school. Recently, a study has shown that parental safety perception is associated with adolescent physical activity levels ${ }^{30}$. This research demonstrated that the perception of traffic safety and lower crime were pos- 
itively associated with active commuting. It should be emphasized that this study investigated the moderate effect of gender and the authors' present evidence that the perception of parents' safety influences the physical activity of adolescents in different ways in boys and girls, depending on the context analyzed.

That strengthens the evidence of the present study is the use of an objective measure of physical activity, which, although not assessing intensity, is an excellent indicator of activities related to active commuting and physical activities in general. The type of data analysis employed is innovative, considering that physical activity and health studies that test moderation and mediation effects are rare.

Thus, the current study examined the association between adolescents' PA and biological and environmental variables with subsequent development of a structural model of the effects of gender, cardiorespiratory fitness, location of residence relative to school, commuting mode to school, walkability and use of public space on weekday PA.

Two variables were associated with PA, use of public spaces and commuting to school. However, the relationship between use of public spaces and PA was weakened when cardiorespiratory fitness was considered in the model, indicating that fitter adolescents were more likely to use public spaces and consequently engage in greater levels of PA.

With regard to active commuting to school, this behavior was associated with two important environmental variables, the distance between the adolescent's residence and the school and walkability of the environment. The relationship between active commuting and walkability was also moderated by gender, where girls were more likely to actively travel to school when the home environment was favorable to active displacement.

\section{Conflict of interest}

The authors declare no conflict of interest.

\section{Funding}

The Project that originates this manuscript was supported by Conselho Nacional de Desenvolvimento Científico e Tecnológico, Brazil. Process number 305200/2013-5.

\section{Author's contributions}

Mello JB collaborated with the design of the research project, data collection, analysis, interpretation and discussion of the results, writing of the text and approval of the final version. Duncan $\mathrm{M}$ colla- borated with the data interpretation and discussion of the results, writing of the text and approval of the final version. Dias A collaborated with the design of the research project and data collection. Bergmann $G$ collaborated with data interpretation and discussion of the results, writing of the text and approval of the final version. Gaya AR collaborated with data interpretation and discussion of the results, supervision of the writing of the text and approval of the final version. Gaya A collaborated with the design of the research project, data interpretation and discussion of the results, supervision of the writing of the text and approval of the final version.

\section{Acknowledgments}

We would like to thank Coordenadoria de Aperfeiçoamento de Pessoal de Nivel Superior (CAPES) for the PhD scholarships of the authors JBM and AFD.

\section{References}

1. Corder K, Winpenny E, Love R, Brown HE, White M, Van Sluijs $\mathrm{E}$. Change in physical activity from adolescence to early adulthood: a systematic review and meta-analysis of longitudinal cohort studies. Br J Sports Med. 2019;53(8):496-503.

2. Myers J,McAuley P, Lavie CJ, Despres JP, Arena R, Kokkinos P. Physical Activity and Cardiorespiratory Fitness as Major Markers of Cardiovascular Risk: Their Independent and Interwoven Importance to Health Status. Prog Cardiovasc Dis. 2015;57(4):306-14.

3. Guthold R, Stevens GA, Riley LM, Bull FC. Global trends in insufficient physical activity among adolescents: a pooled analysis of 298 population-based surveys with $1 \cdot 6$ million participants. Lancet Child Adolesc Heal. 2020;4(1):23-35.

4. Sterdt E, Liersch S, Walter U. Correlates of physical activity of children and adolescents: A systematic review of reviews. Health Educ J. 2014;73(1):72-89.

5. Sallis JF, Cervero RB, Ascher W, Henderson KA, Kraft MK, Kerr J. An ecological approach to creating active living communities. Annu Rev Public Health. 2006;27:297-322.

6. Sallis JF, Prochaska JJ, Taylor WC. A review of correlates of physical activity of children and adolescents. Med Sci Sport Exerc. 2000;32(5):963-75.

7. Rhodes RE, Janssen I, Bredin SSD, Warburton DE, Bauman A. Physical activity: Health impact, prevalence, correlates and interventions. Psychol Health. 2017;32(8):942-75.

8. Tikanmäki M,Tammelin T, Vääräsmäki M, Sipola-Leppänen M, Miettola S, Pouta A, et al. Prenatal determinants of physical activity and cardiorespiratory fitness in adolescence - Northern Finland Birth Cohort 1986 study. BMC Public Health. 2017;17(1):346.

9. Ross A, Searle M. A Conceptual Model of Leisure Time Physical Activity, Neighborhood Environment, and Sense of Community. Environ Behav. 2019;51(6):749-81.

10. Sallis JF, Cerin E, Conway TL, Adams MA, Frank LD, Pratt $\mathrm{M}$, et al. Physical activity in relation to urban environments in 14 cities worldwide: a cross-sectional study. Lancet. 2016;387(10034):2207-17.

11. Smith M, Hosking J, Woodward A, Witten K, MacMillan A, Field A, et al. Systematic literature review of built environment effects on physical activity and active transport - an update and new findings on health equity. Int J Behav Nutr Phys Act. 2017;14(1):158.

12. Bancroft C, Joshi S, Rundle A, Hutson M, Chong C, Weiss CC. Association of proximity and density of parks and 
objectively measured physical activity in the United States: A systematic review. Soc Sci Med. 2015;138:22-30.

13. McGrath LJ, Hopkins WG, Hinckson EA. Associations of Objectively Measured Built-Environment Attributes with Youth Moderate-Vigorous Physical Activity: A Systematic Review and Meta-Analysis. Sport Med. 2015;45(6):841-65.

14. Chillón P, Ortega FB, Ruiz JR, Veidebaum T, Oja L, Mäestu J, et al. Active commuting to school in children and adolescents: An opportunity to increase physical activity and fitness. Scand J Public Health. 2010;38(8):873-9.

15. D'Angelo H, Fowler SL, Nebeling LC, Oh, AY. Adolescent Physical Activity: Moderation of Individual Factors by Neighborhood Environment. Am J Prev Med. 2017;52(6):888-94.

16. Mello JB, Farias VM, Bergmann MLA, Bergmann GG. Number of steps per day and the screening of cardiovascular disease risk factors in adolescents. Mot Rev Educ Física. 2016;22(2):36-43.

17. Bergmann G, Bergmann M, De Castro A, Lorenzi T, Pinheiro E, Moreira R, et al. Use of the 6-minute walk/run test to predict peak oxygen uptake in adolescents. Rev Bras Ativ Fís Saúde. 2014;19(1):64-73.

18. Lee RE, Booth KM, Reese-Smith JY, Regan G, Howard HH. The Physical Activity Resource Assessment (PARA) instrument: Evaluating features, amenities and incivilities of physical activity resources in urban neighborhoods. Int J Behav Nutr Phys Act. 2005;2(1):1-9.

19. Sundquist K, Eriksson U, Kawakami N, Skog L, Ohlsson H, Arvidsson D. Neighborhood walkability, physical activity, and walking behavior: The Swedish Neighborhood and Physical Activity (SNAP) study. Soc Sci Med. 2011;72(8):1266-73.

20. Norman GJ, Nutter SK, Ryan S, Sallis JF, Calfas KJ, Patrick K. Community Design and Access to Recreational Facilities as Correlates of Adolescent Physical Activity and Body-Mass Index. J Phys Act Heal. 2006;3(s1):S118-S128.

21. Edwards N, Hooper P, Knuiman M, Foster S, Giles-Corti B. Associations between park features and adolescent park use for physical activity. Int J Behav Nutr Phys Act. 2015;12(1):21.

22. Reis RS, Hino AAF, Florindo AA, Añez CRR, Domingues MR. Association Between Physical Activity in Parks and
Perceived Environment: A Study With Adolescents. J Phys Act Heal. 2009;6(4):503-509.

23. Monyeki MA, Awotidebe A, Moss SJ, Sparks M, Wushe S, Coetzee B. Relationship between physical activity, body fatness and cardiorespiratory fitness in South African adolescents: The PAHL Study. African J Phys Act Heal Sci. 2017;23(1.2):111-28.

24. Santos MS, Hino AAF, Reis RS, Rodriguez-Añez CR. Prevalência de barreiras para a prática de atividade física em adolescentes. Rev Bras Epidemiol. 2010;13(1):94-104.

25. Camargo EM, Paiva HK, Pacheco HLM, Campos, W. Facilitadores para a prática de atividade física no lazer em adolescentes. Rev Bras Ativ Fis Saúde. 2017;22(6):561-67.

26. Bedimo-Rung AL, Mowen AJ, Cohen DA. The significance of parks to physical activity and public health. Am J Prev Med. 2005;28(2):159-68.

27. Chillón P, Panter J, Corder K, Van Sluijs EMF. A longitudinal study of the distance that young people walk to school. Health Place. 2015;31:133-7.

28. Cohen DA, Ashwood S, Scott M, Overton A, Evenson KR, Voorhees CC. Proximity to School and Physical Activity Among Middle School Girls: The Trial of Activity for Adolescent Girls Study. J Phys Act Heal. 2006;3(s1):S129_ S138.

29. Sallis JF, Conway TL, Cain KL, Carlson JA, Frank LD, Kerr J. Neighborhood built environment and socioeconomic status in relation to physical activity, sedentary behavior, and weight status of adolescents. Prev Med. 2018;110:47-54.

30. Esteban-Cornejo I, Carlson JA, Conway TL, Cain KL, Saelens BE, Frank LD. Parental and Adolescent Perceptions of Neighborhood Safety Related to Adolescents' Physical Activity in Their Neighborhood. Res Q Exerc Sport. 2016;87(2):191-9.

\section{Quote this article as:}

Mello JB, Duncan M, Dias A, Bergmann G, Gaya AR, Gaya A. Biological and urban environmental variables as correlates of adolescents' physical activity. Rev Bras Ativ Fis Saúde. 2020;25:e0134. DOI: 10.12820/rbafs.25e0134 


\section{Supplement 1. Association estimation between biological and environmental variables}

The variables that were associated with the active displacement did not maintain the association after adjusting for gender and age. The association between commuting to school and walkability was confirmed only girls (OR $=1.72 ; 95 \% \mathrm{CI}: 1.09-2.72 ; \mathrm{p}=0.020)$, indicating a moderation effect of gender in the relationship. Regarding distance to school, only adolescents residing at a greater distance (above 1000 meters) from school were more likely to move sedentarily to school (Table 3). Regarding the use of public spaces, none of the variables presented a significant association, even in the adjusted analysis.

Supplement 1 - Association estimation between biological and environmental variables, Porto Alegre’s South zone.

\begin{tabular}{|c|c|c|c|c|c|c|}
\hline & \multicolumn{6}{|c|}{ Passive commuting to school } \\
\hline & OR & CI 95\% & $\mathrm{p}$ & $\mathrm{OR}^{*}$ & CI 95\% & $\mathrm{p}$ \\
\hline \multicolumn{7}{|c|}{ Residence distance to school } \\
\hline$<500$ meters & 1 & - & - & 1 & - & - \\
\hline 501-1000 meters & 2.50 & $0.34-18.33$ & 0.367 & 2.164 & $0.30-15.30$ & 0.439 \\
\hline$>1001$ meters & 6.41 & $1.008-40.80$ & 0.049 & 5.582 & $0.90-34.56$ & 0.065 \\
\hline \multicolumn{7}{|l|}{ Walkability } \\
\hline Displacement-friendly & 1 & - & - & 1 & - & - \\
\hline \multirow[t]{3}{*}{ Non-displacement } & 1.40 & $1.02-1.94$ & 0.035 & 1.296 & $0.96-1.74$ & 0.088 \\
\hline & \multicolumn{6}{|c|}{ Does not use public space to PA } \\
\hline & OR & CI 95\% & $\mathrm{p}$ & $\mathrm{OR}^{*}$ & CI 95\% & $\mathrm{p}$ \\
\hline \multicolumn{7}{|c|}{ Residence distance to nearest square/park } \\
\hline$<250$ meters & 1 & - & - & 1 & - & - \\
\hline$\geq 250$ meters & 1.02 & $0.81-1.29$ & 0.831 & 1.02 & $0.72-1.44$ & 0.903 \\
\hline \multicolumn{7}{|c|}{ Have square/park in buffer (at least one) } \\
\hline Yes & 1 & - & - & 1 & - & - \\
\hline Not & 1.04 & $0.85-1.27$ & 0.684 & 1.16 & $0.80-1.68$ & 0.424 \\
\hline \multicolumn{7}{|c|}{ Have square/park with PA attributes (without playground) } \\
\hline Yes & 1 & - & - & 1 & - & - \\
\hline Not & 0.96 & $0.77-1.18$ & 0.717 & 0.83 & $0.55-1.23$ & 0.362 \\
\hline
\end{tabular}

$\mathrm{OR}=$ Odds ratio; $\mathrm{CI} 95 \%$ = Confidence interval of 95\%; $\mathrm{p}=$ significance level; $\mathrm{OR}^{*}=$ Odds ratio adjusted to gender; $\mathrm{PA}=$ physical activity . 